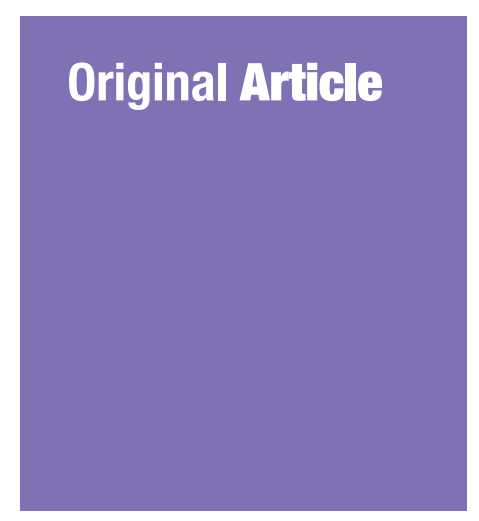

Submitted: 13 Jan 2016 Accepted: 7 Nov 2016 Online: 24 Feb 2017

\section{Interference Effect of Prior Explicit Information on Motor Sequence Learning in Relapsing-Remitting Multiple Sclerosis Patients}

\author{
Nahid ZaHIRI ${ }^{1}$, Iraj AbollahI ${ }^{1}$, Seyed Massood NabaVI ${ }^{2}$, Fatemeh \\ EhSANI ${ }^{3}$, Amir Masoud Arab', Ina Shaw ${ }^{4}$, Ardalan Shariat ${ }^{5}$, \\ Brandon S ShaW ${ }^{4}$, Maryam Dastoorpoor ${ }^{6}$, Mahmoud DanAEE ${ }^{7}$, \\ Bahram SANGELAJI ${ }^{8}$
}

$1 \quad$ Department of Physiotherapy, University of Social Welfare and Rehabilitation Sciences, Tehran, Iran

2 Department of Neurology, MS Research Unit, Shahed University, Tehran, Iran

$3 \quad$ Neuromuscular Rehabilitation Research Center, Semnan University of Medical Sciences, Semnan, Iran

$4 \quad$ Department of Sport and Movement Studies, University of Johannesburg, Doornfontein, Johannesburg, Republic of South Africa

5 Department of Occupational Health, Faculty of Medicine and Health Sciences, Universiti Putra Malaysia, Malaysia

6 Department of Epidemiology and Biostatistics, Faculty of Public Health, Ahvaz Jundishapur University of Medical Sciences, Ahvaz, Iran

$7 \quad$ University of Malaya Centre of Addiction Sciences (UMCAS), Malaysia

8 School of Physiotherapy, Otago University, Dunedin, New Zealand

To cite this article: Zahiri N, Abollahi I, Nabavi SM, Ehsani F, Masoud Arab A, Shaw I, Shariat A, Shaw BS, Dastoorpoor M, Danaee M, Sangelaji B. Interference effect of prior explicit information on motor sequence learning in relapsing-remitting multiple sclerosis patients. Malays J Med Sci. 2017;24(1):69-80. https://doi.org/10.21315/ mjms2017.24.1.8

To link to this article: https://doi.org/10.21315/mjms2017.24.1.8

\begin{abstract}
Background: Multiple sclerosis (MS) is the most widespread disabling neurological condition in young adults around the world. The purpose of this study was to investigate the impact of explicit information (EI) on motor-sequence learning in MS patients.

Methods: Thirty patients with relapsing-remitting MS (RRMS), age: 29.5 (SD = 5.6) years and 30 healthy gender-, age-, and education-matched control group participants, age: 28.8 $(S D=6.0)$ years, were recruited for this study. The participants in the healthy group were then randomly assigned into an EI $(n=15)$ group and a no-EI $(n=15)$ group. Similarly, the participants in the control group were then randomly assigned into EI $(n=15)$ and no-EI $(n=15)$ groups. The participants performed a serial reaction time (SRT) task and reaction times. A retention test was performed after 48 hours.

Results: All participants reduced their reaction times across acquisition (MS group: 46.4 (SD = 3.3) minutes, $P<0.001$, and healthy group: $39.4(\mathrm{SD}=3.3)$ minutes, $P<0.001)$. The findings for the within-participants effect of repeated measures of time were significant $\left(F_{(5.06}\right.$, $\left.{ }_{283.7)}=71.33 . P<0.001\right)$. These results indicate that the interaction between group and time was Significant $\left(F_{(5.66}=6.44 . P<0.001\right)$, which indicated that the reaction time in both groups was significantly changed between the MS and healthy groups across times (B1 to B10). The main effect of the group (MS and healthy) $\left(F_{(1,56)}=22.78 . P<0.001\right)$ and also the main effect of no-EI vs $\mathrm{EI}\left(\mathrm{F}_{(1,56)}=4.71 . P<0.001\right)$ were significant.
\end{abstract}


Conclusion: This study demonstrated that that RRMS patients are capable of learning new skills, but the provision of EI prior to physical practice is deleterious to implicit learning. It is sufficient to educate MS patients on the aim and general content of the training and only to provide feedback at the end of the rehabilitative session.

Keywords: motor learning, motor task, neurological disease, serial reaction time task, multiple sclerosis

\section{Introduction}

Multiple sclerosis (MS) is the most common inflammatory demyelinating disease of the central nervous system in young adults and is usually diagnosed in individuals between the ages of 20 and 40 years. This disease is almost twice as common in women as in men. MS affects 2.5 million persons worldwide and approximately 350,000 Americans with as many as 300 persons being diagnosed each week $(2,4)$.

The onset of the disease at a young age causes long-term disability and significant psychological problems for the patients and their families (5). This early onset also results in an increased need to provide appropriate treatment and rehabilitation techniques to reduce disability and improve one's quality of life (5-7).

A wide range of rehabilitative approaches have been employed to reduce disability and improve one's quality of life (1). These approaches range from more traditional strategies to newer techniques emphasising the learning and practice of functional motor skills $(1,8-9)$, as it has been found that practice is critical for mastery of motor skills (10). In this approach, the rehabilitation therapist acts as a facilitator, using many kinds of techniques such as instructions, physical or verbal guidance, and feedback to improve learning (11). Rehabilitation therapists use these instructions to guide their patients toward an optimal motor solution (12). As such, rehabilitation therapists dedicate considerable therapeutic time providing instruction to patients. However, regardless of the enormous amount of effort and time devoted to training individuals throughout rehabilitation, there are not many studies that have considered the effect of explicit information (EI) on the neurologic patients' implicit learning $(4,10)$. In addition, to date, there has been no general agreement on how implicit motor skill learning is supported by instructions of verbal EI in any population.

There are two main types of learning: implicit and explicit. Explicit learning deals with knowledge of facts, events, and episodes and may be formed very quickly (even in one exposure) and is directly accessible to conscious recollection (7). In turn, implicit learning is the capacity to acquire motor learning through physical practice and is not directly accessible to conscious recollection (13-16). One of the most common paradigms used to study implicit learning is serial reaction time (SRT) tasks (17). SRT tasks have both perceptual and motor learning components and require an individual to respond to a stimulus with a motor response (18-21).

The influence of EI on implicit learning has been disparately reported in the literature $(12,22-27)$. The experimental data are rather controversial in that some investigators report the beneficial effects of EI on implicit motor learning $(12,24,26)$, while other studies show detrimental effects $(22-23,27)$. However, it seems that these contradictory findings may result from combined factors, such as task differences, type, timing and salience of EI, and personal characteristics (27)

Some studies suggest that explicit learning has a detrimental effect on implicit learning when cognitive capacity and working memory are reduced, such as in a cerebral vascular accident or healthy aged participants (27-29). These studies imply that simple practice without instruction and with general performance feedback, as opposed to explicit instruction, may lead to more efficient performance. This explanation could have direct implications for instructional techniques in applied settings (23). Studies in MS patients suggest that the ability of MS patients to learn motor skills is partially preserved (30-31). However, the impact of EI on implicit learning in this population has not been considered in any studies.

As such, the purpose of this study was to investigate the impact of EI on motor-sequence learning in MS patients. It compared the effect of simple non-instructed practice of repeated sequences with general performance feedback and explicit instruction on motor-sequence learning in MS patients. 
Original Article | Motor sequence learning and multiple sclerosis

\section{Materials and Methods}

\section{Selection and description of participants}

Thirty MS patients and 30 healthy people as the control group were recruited (Table 1). The participants in the healthy group were then randomly assigned into an EI $(n=15)$ group and a no-EI $(n=15)$ group. Similarly, the participants in the control group were then randomly assigned into EI $(n=15)$ and no-EI $(n=15)$ groups.

To determine the sample size, the following formula was used (33):

$$
n=\frac{2\left(Z_{1-a}+Z_{1-b}\right)^{2}}{d^{2}} \times \sigma^{2}
$$

In the formula, $\mathrm{n}$ represented the sample size (each group). $Z 1-\alpha / 2$ represented the value from the standard normal distribution $(P \leq 0.05)$ that was equal to $1.960 . Z 1-\beta=$ $1-\beta$ was the selected power. With a power of 80 , it equaled 0.84 . $\sigma 2$ was the standard deviation of the outcome in prior studies and was thus 2. d was the standard deviation of the difference in the outcome (e.g., the difference based on measurements over time or the difference between matched pairs) and was 1. Therefore, the intervention and control groups were calculated as follows: $n=2(1.96+0.84)^{2} \times 2 / 1=31.36 \cong 30$

The eligibility criteria for participants with MS included: patients affected by definite relapsing-remitting multiple sclerosis who were in a stable phase of the disease, without relapses in the last three months, and younger than 60 years of age. All participants included in this study were right-handed.

Exclusion criteria for all participants were: visual impairment, cerebellar manifestation (e.g., gait ataxia, nystagmus, tremor), other neurological, psychiatric, severe general disease or alcoholism, mini-mental state examination (MMSE) < 21, treatment with high-dose methyl prednisolone within the last four weeks, current antipsychotic or antiepileptic medication (except long duration previous usage of antidepressive and anxiolytic drugs), and the recent introduction of psychoactive drugs.

The study was approved by the Institutional Review Boards of the University of Social Welfare and Rehabilitation Science (USWRS), Iran, and written informed consent was obtained from all participants. The study was conducted in the USWRS physiotherapy clinic, located in Tehran from September 2011 to May 2012. The study was conducted according to the principles of the Declaration of Helsinki.

Table 1. Participants demographics $(N=60)$

\begin{tabular}{|c|c|c|c|c|}
\hline Variables & & $\begin{array}{c}\text { MS Group }(n=30) \\
n(\%)\end{array}$ & $\begin{array}{c}\text { Control Group }(n=30) \\
n(\%)\end{array}$ & $\begin{array}{l}\text { Total } \\
n(\%)\end{array}$ \\
\hline Age $\left(\right.$ years) ${ }^{\mathrm{a}}$ & & $29.5(5.6)$ & $28.8(6.0)$ & $29.1(5.9)$ \\
\hline \multirow[t]{2}{*}{ Gender } & Male & $6(20.0)$ & $6(20.0)$ & $12(20.0)$ \\
\hline & Female & $24(80.0)$ & $24(80.0)$ & $48(80.0)$ \\
\hline $\mathrm{EDSS}^{\mathrm{b}}$ & & $1.5(0.4)$ & - & $1.5(0.4)$ \\
\hline $\begin{array}{l}\text { MS }^{\mathrm{c}} \text { Duration } \\
\text { (months) }\end{array}$ & & $64.4(48.4)$ & - & $64.4(48.4)$ \\
\hline
\end{tabular}

${ }^{\mathrm{a}}$ Mean (SD)

${ }^{\mathrm{b}}$ Expanded disability status scale

'MS: multiple sclerosis 


\section{Procedures}

All participants performed the SRT task. In this task, four squares with different colours (yellow, red, blue, and green) appeared on the computer monitor placed directly in front of each participant. The participants were required to press the keys on a keyboard that were colour-coded yellow, red, green, or blue, corresponding to the appropriately coloured square immediately after observing it. Only one coloured square appeared at a time. Once the correct key was pressed, the next coloured square appeared. The coloured square remained on the screen until the correct selection was made. After every key press, time data (reaction time (RT)) were stored.

This test consisted of two types of sequences: repeating and random. Repeating sequences consisted of a pattern appearing in an ordered manner (Blue-Yellow-Red-Blue-GreenYellow-Blue-Red-Yellow-Green), while random sequences consisted of a pattern appearing in an unordered manner. To familiarise the participants with the test, a block of random sequences was performed $(1$ block $=10$ sequence $=100$ trials). The main test consisted of two sequence blocks, one random block, two sequence blocks, one random block, and two sequence blocks. After 48 hours, the test was repeated to determine retention. The retention test consisted of two sequence blocks. Each block of reactions consisted of 10 sequences of 10 trials each. When each block of reactions ended, a 1-2 minute rest period was provided. Participants were instructed to respond as fast and accurately as possible. To ensure random concealment, EI about sequence patterns was randomly given to 30 participants (EI group), whereas 30 participants were unaware of the sequences before the test (no-EI group). Randomisation was ensured by the principal investigator using a random numbers table. This ensured the blinding of the participants.

In the EI groups, the tester orally provided as many repetitions of the instructions as necessary and asked participants to complete verbal recalls of the repeating sequence. The recall was judged complete if the repeated sequence was identified by the participants well enough. As such, all participants in this group were given intentional instructions and full explicit knowledge of the pattern prior to the test. For the no-EI groups, following their intentional test on day two, an interview was performed to assess subjective explicit awareness by asking participants if they had ever noticed a pattern. In addition, recall was determined by asking participants to complete a four-element fragment of the sequence by filling in one blank colour with one of four colour choices. If they were unsure, participants were encouraged to make their best guess. A participant was excluded from the test if he/she could recognise and recall. The technician that conducted this aspect of the test was blinded to the group allocation of participants.

\section{Statistical analysis}

Statistical analysis was done with the Statistical Product and Service Solutions (SPSS) software (IBM SPSS Statistics 21.0), with the significance level fixed at $P<0.05$. For the SRT task, the primary outcome measure was reaction time (RT; reaction plus movement time), which was calculated as the time between the stimulus onset to the completion of the reaction. The RT was stored for each trial.

The median RT was calculated for each 10-element sequence trial. The calculation of median RT values for each sequence trial reduced the sensitivity of the measure to very large or very small values. RTs were then summarised by calculating the mean and median for each block of reactions. This procedure was performed for both random and repeated sequences and represented the absolute RT. Then, sequence learning (SL) was calculated as the difference in RT between the first (B1) and the last block (B10) $\{\mathrm{B} 1-\mathrm{B} 10\}$ subtracting the component due to non-specific learning ( $\mathrm{SL}=$ $(\mathrm{S} 1-\mathrm{S} 10)-(\mathrm{R} 2-\mathrm{R} 4))$ and in this formula, the sequence block was shown by "S" and random block was shown by "R."

To assess differences in the initial performance between the two groups, Student's $t$-tests were performed on RT in B1 (baseline). Then, to evaluate the dynamics of the explicit sequence learning process, a two-way repeated measures ANOVA (RM-ANOVA) was performed on the RT using the healthy factor group (patient with MS and controls) and learning group (EI and no-EI groups) as the betweenparticipants factor and block (B1-B1O) as the within-participants factor. To evaluate sequence learning and the effect of EI, student's $t$-tests were used between the two groups and subgroups. Alpha levels were set at $P \leq 0.05$ for statistical significance.

The participants completed all components necessary for the data analyses, thus 
Original Article | Motor sequence learning and multiple sclerosis

demonstrating $100 \%$ compliance. None of the participants suffered from any deleterious effects as a result of the experiment.

\section{Results}

The RM-ANOVA was applied to assess whether there were group (MS and healthy) and time differences in the RT in both no-EI ( $n$ $=30)$ and EI $(n=30)$. Mauchly's test was used to evaluate the sphericity assumption, and the results showed that the sphericity assumption for the RT was violated $(\chi 2=216.125$, $P<0.01)$. Therefore, the $F$-value was adjusted by a Greenhouse-Geisser correction.

The findings for the within-participants effect of repeated measures of time were significant $\left(F_{(5.06,283.7)}=71.33 . \quad P<0.001\right.$. $\left.\eta^{2}=0.560\right)$. These results indicate that the interaction between group and time was significant $(F, \quad=6.44 . \quad P<0.001$. $\left.\eta^{2}=0.103\right)$, which indicated that the RT in both groups was significantly changed between the MS and healthy groups across times (B1 to B10). The main effect of group (MS and healthy) $\left(\mathrm{F}_{(1,56)}=22.78 . P<0.001 . \eta^{2}=0.289\right)$ and the main effect of non-EI vs EI $\left(\mathrm{F}_{(1,56)}=4.71\right.$. $P<0.001 . \eta^{2}=0.078$ ) were significant.

To test the related hypothesis, a post-hoc test (Bonferroni) was applied to compare the mean scores (Table $2-5$ ). The data demonstrated that in this study all participants could reduce their RTs across this task.

Table 2. Estimated marginal means of reaction times (in milliseconds) in MS and Healthy groups $(N=60)$ for two explicit-learning conditions

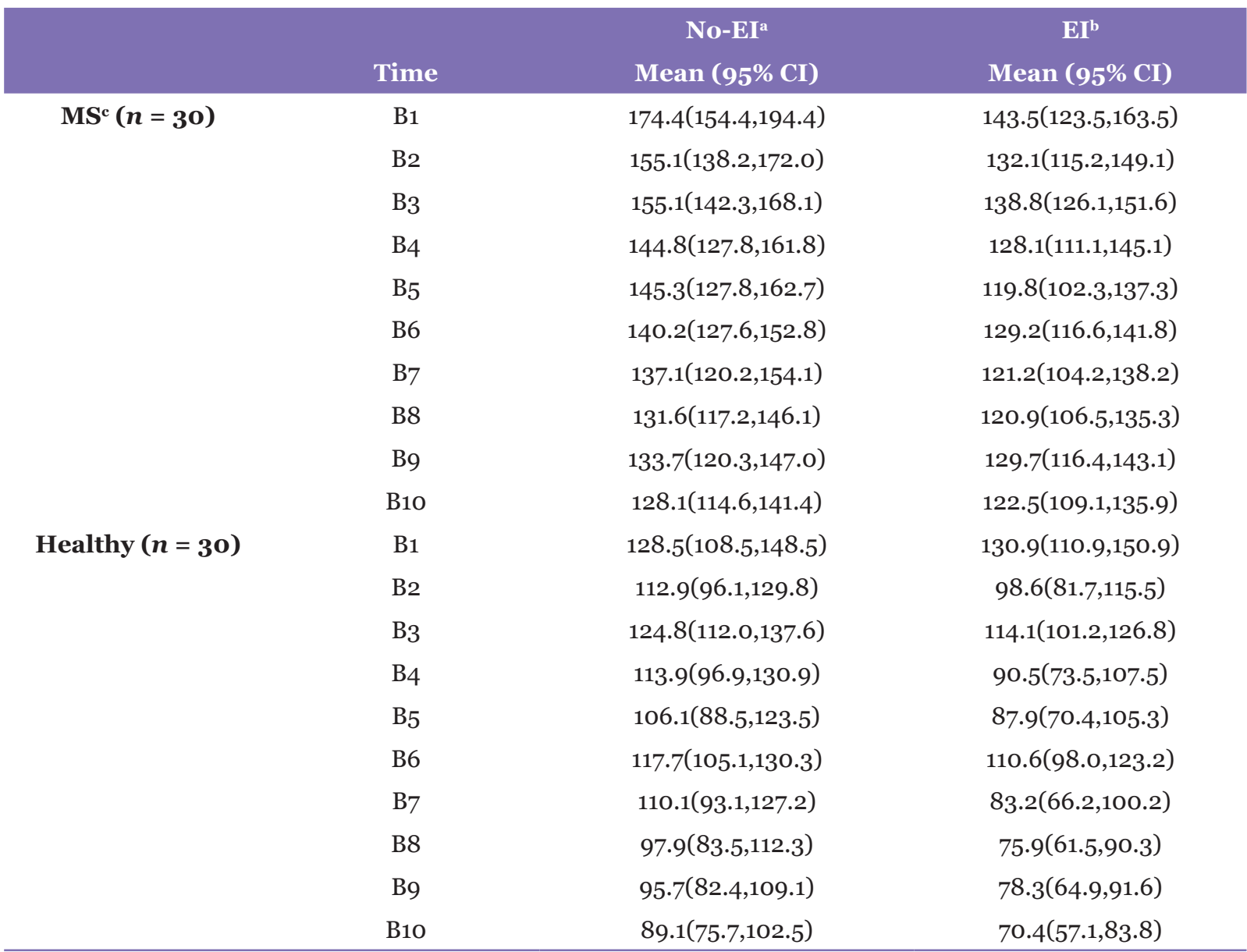

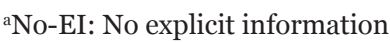

bI: Explicit information

'MS: multiple sclerosis 
Table 3. The pairwise comparisons over time for two explicit-learning conditions $(N=60)$

\begin{tabular}{|c|c|c|c|c|c|}
\hline \multirow[b]{2}{*}{ (I) time } & \multirow[b]{2}{*}{ (J) time } & \multicolumn{2}{|c|}{ Non-EIa } & \multicolumn{2}{|l|}{$\mathbf{E I}^{\mathbf{b}}$} \\
\hline & & $\begin{array}{l}\text { Mean difference } \\
(95 \% \mathrm{CI})\end{array}$ & $P$-value ${ }^{\mathrm{c}}$ & $\begin{array}{l}\text { Mean difference } \\
(95 \% \mathrm{CI})\end{array}$ & $P$-value \\
\hline 1 & 2 & $17.4(8.1,26.9)$ & 0.000 & $21.8(12.4,31.3)$ & 0.000 \\
\hline 1 & 3 & $11.5(-2.5,25.5)$ & 0.288 & $10.8(-3.1,24.8)$ & 0.447 \\
\hline 1 & 4 & $22.1(8.8,35.4)$ & 0.000 & $27 \cdot 9(14 \cdot 7,41.2)$ & 0.000 \\
\hline 1 & 5 & $25.8(13.5,38.1)$ & 0.000 & $33 \cdot 4(21.1,45 \cdot 7)$ & 0.000 \\
\hline 1 & 6 & $22.5(7 \cdot 4,37 \cdot 7)$ & 0.000 & $17.3(2.2,32.5)$ & 0.010 \\
\hline 1 & 7 & $27.8(13.2,42.6)$ & 0.000 & $35.0(20.3,49.7)$ & 0.000 \\
\hline 1 & 8 & $36.7(23.1,50.4)$ & 0.000 & $38.8(25.1,52.5)$ & 0.000 \\
\hline 1 & 9 & $36.7(24 \cdot 3,49 \cdot 3)$ & 0.000 & $33.2(20.7,45 \cdot 7)$ & 0.000 \\
\hline 1 & 10 & $42.9(29.5,56.3)$ & 0.000 & $40.7(27 \cdot 3,54.2)$ & 0.000 \\
\hline 2 & 3 & $-5 \cdot 9(-16.2,4 \cdot 3)$ & 1.000 & $-11.1(-21.3,-0.8)$ & 0.022 \\
\hline 2 & 4 & $4 \cdot 7(-5 \cdot 2,14.6)$ & 1.000 & $6.1(-3.8,16.1)$ & 1.000 \\
\hline 2 & 5 & $8.4(-1.5,18.3)$ & 0.237 & $11.5(1.6-21.5)$ & 0.009 \\
\hline 2 & 6 & $5.1(-6.2,16.4)$ & 1.000 & $-4 \cdot 5(-15 \cdot 8,6.7)$ & 1.000 \\
\hline 2 & 7 & $10.4(-1.1,22.1)$ & 0.135 & $13 \cdot 1(1.6,24 \cdot 7)$ & 0.011 \\
\hline 2 & 8 & $19.3(9.4,29.2)$ & 0.000 & $16.9(7.1,26.8)$ & 0.000 \\
\hline 2 & 9 & $19.3(9.8,28.9)$ & 0.000 & $11.3(1.8,20.9)$ & 0.006 \\
\hline 2 & 10 & $25 \cdot 4(15 \cdot 5,35 \cdot 4)$ & 0.000 & $18.9(8.9,28.9)$ & 0.000 \\
\hline 3 & 4 & $10.6(-0.2,21.4)$ & 0.060 & $17.1(6.3,27.9)$ & 0.000 \\
\hline 3 & 5 & $14 \cdot 3(3 \cdot 4,25 \cdot 2)$ & 0.001 & $22.5(11.7,33.5)$ & 0.000 \\
\hline 3 & 6 & $11.0(3.8,18.3)$ & 0.000 & $6.5(-0.8,13.8)$ & 0.147 \\
\hline 3 & 7 & $16.3(5 \cdot 1,27 \cdot 7)$ & 0.000 & $24.2(12.8,35.6)$ & 0.000 \\
\hline 3 & 8 & $25 \cdot 2(15 \cdot 3,35 \cdot 2)$ & 0.000 & $27.9(18.1,37 \cdot 9)$ & 0.000 \\
\hline 3 & 9 & $25.2(15 \cdot 3,35 \cdot 2)$ & 0.000 & $22.4(12.5,32.3)$ & 0.000 \\
\hline 3 & 10 & $31.4(21.8,41.1)$ & 0.000 & $29.9(20.3,39.6)$ & 0.000 \\
\hline 4 & 5 & $3.73(-3.1,-10.6)$ & 1.000 & $5 \cdot 5(-1.4,12.3)$ & 0.377 \\
\hline 4 & 6 & $0.43(-10.3,11.1)$ & 1.000 & $-10.1(-21.3,0.1)$ & 0.056 \\
\hline 4 & 7 & $5 \cdot 76(-4,15 \cdot 5)$ & 1.000 & $7 \cdot 1(-2.6,16.8)$ & 0.671 \\
\hline 4 & 8 & $14 \cdot 6(5 \cdot 2,24)$ & 0.000 & $10.8(1.5,20.3)$ & 0.009 \\
\hline 4 & 9 & $14 \cdot 6(4 \cdot 9,24 \cdot 4)$ & 0.000 & $5 \cdot 3(-4 \cdot 4,15 \cdot 1)$ & 1.000 \\
\hline 4 & 10 & $20.8(11.1,30.5)$ & 0.000 & $12.8(3.1,22.5)$ & 0.001 \\
\hline 5 & 6 & $-3 \cdot 3(-14 \cdot 3,7 \cdot 7)$ & 1.000 & $-16.1(-27.1,-5.1)$ & 0.000 \\
\hline 5 & 7 & $2.0(-6.5,10.6)$ & 1.000 & $1.6(-6.9,10.2)$ & 1.000 \\
\hline 5 & 8 & $10.9(1.5,20.3)$ & 0.008 & $5 \cdot 4(-4.1,14.8)$ & 1.000 \\
\hline 5 & 9 & $10.9(1.3,20.5)$ & 0.011 & $-0.1(-9.8,9.4)$ & 1.000 \\
\hline 5 & 10 & $17.0(7.7,26.4)$ & 0.000 & $7 \cdot 4(-2.1,16.7)$ & 0.403 \\
\hline 6 & 7 & $5 \cdot 3(-6.7,17 \cdot 3)$ & 1.000 & $17 \cdot 7(5 \cdot 7,29 \cdot 7)$ & 0.000 \\
\hline 6 & 8 & $14 \cdot 2(4 \cdot 1,24 \cdot 3)$ & 0.001 & $21.4(11.4,31.6)$ & 0.000 \\
\hline
\end{tabular}


Original Article | Motor sequence learning and multiple sclerosis

Table 3. (continued)

\begin{tabular}{|c|c|c|c|c|c|}
\hline \multirow[b]{2}{*}{ (I) time } & \multirow[b]{2}{*}{ (J) time } & \multicolumn{2}{|c|}{ Non-EI ${ }^{a}$} & \multicolumn{2}{|l|}{$\mathbf{E I}^{\mathbf{b}}$} \\
\hline & & $\begin{array}{l}\text { Mean difference } \\
(95 \% \mathrm{CI})\end{array}$ & $P$-value & $\begin{array}{l}\text { Mean difference } \\
(95 \% \mathrm{CI})\end{array}$ & P-value \\
\hline 6 & 9 & $14.2(5.1,23.5)$ & 0.000 & $15 \cdot 9(6.6,25.2)$ & 0.000 \\
\hline 6 & 10 & $20.3(10.4,30.3)$ & 0.000 & $23 \cdot 4(13 \cdot 5,33 \cdot 4)$ & 0.000 \\
\hline 7 & 8 & $8.8(0.7,17.1)$ & 0.021 & $3.8(-4.4,12.1)$ & 1.000 \\
\hline 7 & 9 & $8.9(-1.6,19.4)$ & 0.232 & $-1.8(-12.3,8.7)$ & 1.000 \\
\hline 7 & 10 & $15 \cdot 0(5.8,24 \cdot 3)$ & 0.000 & $5 \cdot 7(-3 \cdot 5-15)$ & 1.000 \\
\hline 8 & 9 & $0.1(-5 \cdot 9,5 \cdot 9)$ & 1.000 & $-5.5(-11.5,0.3)$ & 0.089 \\
\hline 8 & 10 & $6.2(1.3,11)$ & 0.002 & $1.9(-2.9,6.8)$ & 1.000 \\
\hline 9 & 10 & $6.1(2.1,10.2)$ & 0.000 & $7 \cdot 5(3 \cdot 4,11.6)$ & 0.000 \\
\hline
\end{tabular}

${ }^{\text {aNN}}$-EI: No explicit information

${ }^{\mathrm{b}} \mathrm{EI}$ : Explicit information

'The mean difference is significant at the $P \leq 05$ level. Adjustment for multiple comparisons: Bonferroni.

\section{Discussion}

This study found that all the participants could reduce their RTs across acquisition. EI disrupted implicit learning in MS patients, but the control participants' learning was facilitated in the EI group. RRMS patients are capable of learning new skills, but the provision of EI prior to the physical practice of repeated sequences is deleterious to implicit learning. This study's results showed that during acquisition performance, MS patients were not able to make use of EI in the EI group. The participants established poorer SRT task learning than MS patients in the no-EI group.

Rao et al. reported that motor slowing is not the only factor responsible for a reaction delay, suggesting an associated cognitive slowing (34). In turn, Stoquart-Elsankari (35) showed that the action slowing of MS patients is mainly related to attentional deficit and subtle motor slowness. Stoquart-Elsankari's study showed that MS patients are unable to maintain high levels of rapid actions (attentional deficit). StoquartElsankari's study also observed this slowness even in patients without motor deficits on clinical examination. Following this result, StoquartElsankari (35) proposed subtle motor slowing in these patients as a reason for the findings. The relationship between reaction lengthening and attention disorders remains unclear, although both are frequently associated (36). In general, several factors, such as motor slowing, perceptual, attentional and cognitive deficits, and overall mental slowing, may account for reaction slowing. However, these mechanisms influence the pattern of impairment in different ways (36).

The present results showed that the sampled RRMS patients were able to significantly reduce RT values with sequence repetition during an SRT task, indicating the capability of motor learning in MS patients. However, the improvement observed was significantly lower than in the control group. This finding is in agreement with the results of Tomassini et al. (31) and Stoquart-Elsankari (35) indicating that motor skill learning is partially preserved in MS patients.

An interesting finding of the present study was that the provision of EI to MS patients and control group participants resulted in opposite effects. In this regard, EI facilitated implicit learning in the control participants in the EI group, as evidenced by the larger decreases in RT compared to the control participants in the no-EI group and MS patients in both the EI and no-EI groups. This study's beneficial effect of EI on the participants' acquisition performance without neurologic damage is in agreement with previous findings (12, 24, 26). However, other studies do exist that have not found improved implicit learning with prior explicit knowledge (22-23, 25). Green and Flowers (22-23) found that instructions prior to practice reduced implicit learning on a computer-simulated probabilistic catching task. Green and Flowers (22-23) propose that EI had a particular interference effect on performance. However, the level of task 
complexity may explain the differences in studies that have not found improved implicit learning with prior explicit knowledge.

Another explanation for the differences in studies that have and have not found improved implicit learning with prior explicit knowledge might be due to prior explicit knowledge facilitating implicit learning only when the instructions being learned are relatively simple. Our findings contradict with the results shown in previous work by Reber and Squire (25) in that their study did not find a benefit for EI provided to healthy participants before SRT task practice. It seems this difference may be due to the failure of Reber and Squire (25) to ensure that participants gained some degree of EI of the sequence before practice. In their study, investigators had participants only watch the repeating sequence and with this method, provided EI. This form of EI likely lacked salience and interest for participants, which could have prevented them from using it. In turn, the present study gave a verbal explanation about the repeating pattern in EI groups, followed by a request to the participants to recall and recognise the repeated sequence prior to practice.

This study's results showed that during acquisition performance, MS patients were not able to make use of EI in the EI group. In fact, they established poorer SRT task learning than MS patients in the no-EI group. This pattern suggests an interference effect of EI on implicit motor-sequence learning. As such, it appears that in MS patients, EI is less helpful in the development of a motor plan than is discovering a motor solution using the implicit system alone.

Explicit sequence learning is based on the conscious recollection of previous experiences and can occur when EI is provided for participants followed by a request for them to recognise and then recall a test sequence. This process has been shown to activate the front parietal network in both contralateral and ipsilateral hemispheres (37-40) and enhance the connection between the front parietal circuits of the left and right hemispheres, as established by intra-hemispheric white matter pathways, such as the left and right superior longitudinal fasciculus (SLF). Thus, these intra-hemispheric connections and the main inter-hemispheric connection in the brain linking homologous areas the two hemispheres, i.e., the corpus callosum (CC), has a role in this process. It is essential to note that pathological damage in both SLF and CC has been demonstrated to occur in MS patients (30).
Moreover, the learning impairment observed in these patients could also be due to the slowed information processing (41) and impaired working memory capacity (42), which can be related to alterations in the functional connectivity patterns involving different neural networks (43-45). Changes in brain connectivity in MS patients have been shown by diffusion tensor imaging in full (DTI)-based fiber tracking (46-47) and functional magnetic resonance imaging (MRI) (43, 48-49).

It can also be assumed that EI places an increased demand on the central executive system (CES). The role of this system in working memory is remarkable during cognitive challenges since the CES is responsible for allocating appropriate attentional resources. Researchers such as D'Esposito et al. (50) conclude that MS patients have a working memory deficit and that impairments in the speed of information processing reflect an impaired CES. As such, any reduction in performance observed during explicit learning reflects the inability of the CES to allocate sufficient attentional resources to support accurate performance. Additional research has also postulated that working memory impairments in MS may also be due to impairments in the speed and capacity of central information processing (51).

Of course, the theory of plasticity and the results of Tomassini et al. (31) should be considered when selecting appropriate therapeutic approaches for motor-sequence learning in MS patients. These researchers concluded that the learning of new motor skills stimulates mechanisms of brain plasticity, and this factor provides a background for the recovery of function of MS patients. Accordingly, if the MS patients in the present study had received more practice, there may be an enhanced learning effect.

Another important finding was that the control and MS patients in the no-EI group did equally well in their acquisition of learning, although the MS patients performed this task slower than the control group. Moreover, it should be noted that implicit memory is more stable against the change of task (52) and this stability can help to ensure learning.

This study was not able to control the degree of depression and visual impairment in patients with MS, which could have affected the reactions. The generalisability of this study is reduced by the inclusion of only one type of MS (relapse-remitting). 
Original Article | Motor sequence learning and multiple sclerosis

\section{Conclusion}

The present study's results indicate that RRMS patients are capable of learning new skills. However, the present study proposes that EI prior to physical practice is deleterious to implicit learning in MS patients. These results suggest that when selecting an appropriate therapeutic approach in rehabilitation protocols, it is sufficient to educate MS patients on the aim and general content of the training and provide feedback only at the end of a rehabilitative session.

\section{Acknowledgements}

The authors would like to acknowledge Mohammad A Sanjari for his technical support and all the students who participated in this study.

\section{Conflict of Interests}

The authors did not have any conflicts of interests.

\section{Funds}

There was no financial support for this survey.

\section{Authors' Contributions}

Conception and design: NZ, AS, BS

Analysis and Interpretation of the data: AS, MDan, BS

Drafting of the article: IA, SMN

Critical revision of the article for important intellectual content: FE, BSS

Final approval of the article: IS

Provision of study materials or patients: SMN

Statistical expertise: MDas, MDan

Obtaining of funding: IA

Administrative, technical, or logistic support: AMA

Collection and assembly data: BSS, MDas

\section{Correspondence}

Dr Bahram Sangelaji

PhD candidate

School of Physiotherapy,

University of Otago,

325 Great King,

Dunedin, 9016 New Zealand.
Tel: 006434799619

Fax: 006434798414

E-mail: bahram.sangelaji@otago.ac.nz

\section{References}

1. Gutierrez GM, Chow JW, Tillman MD, McCoy SC, Castellano V, White LJ. Resistance training improves gait kinematics in persons with multiple sclerosis. Arch Phys Med Rehabil. 2005;86(9):1824-1829. https://dx.doi.org/10. 1016/j.apmr.2005.04.008.

2. Giannini MJ, Bergmark B, Kreshover S, Elias E, Plummer C, O'Keefe E. Understanding suicide and disability through three major disabling conditions: Intellectual disability, spinal cord injury, and multiple sclerosis. Disabil Health $J$. 2010;3(2):74-78. https://dx.doi.org/10.1016/j. dhjo.2009.09.001

3. Calabrese P. Neuropsychology of multiple sclerosis. J Neurol. 2006;253(5):10-15. https:// dx.doi.org/10.1007/s00415-006-1103-1

4. DeBolt LS, McCubbin JA. The effects of homebased resistance exercise on balance, power, and mobility in adults with multiple sclerosis1. Arch Phys Med Rehabil. 2004;85(2):290-297. https://dx.doi.org/10.1016/j.apmr.2003.06.003

5. Sangelaji B, Nabavi SM, Estebsari F, Banshi MR, Rashidian H, Jamshidi E, et al. Effect of combination exercise therapy on walking distance, postural balance, fatigue and quality of life in multiple sclerosis patients: a clinical trial study. Iranian Red Crescent Medical Journal. 2014;16(6):171-178. https://dx.doi.org/ 10.5812/ ircmj.17173

6. Kargarfard M, Lam ET, Shariat A, Shaw I, Shaw BS, Tamrin SB. Efficacy of massage on muscle soreness, perceived recovery, physiological restoration and physical performance in male bodybuilders. J Sports Sci. 2016 May 18;34(10):959-965.

7. Kraft GH. Rehabilitation still the only way to improve function in multiple sclerosis. Lancet. 1999;354(5):201-207. 
8. Pilutti LA, Lelli DA, Paulseth JE, Crome M, Jiang S, Rathbone MP, et al. Effects of 12 weeks of supported treadmill training on functional ability and quality of life in progressive multiple sclerosis: a pilot study. Arch Phys Med Rehabil. 2011;92(1):31-36. https://dx.doi.org/10.1016/j. apmr.2010.08.027

9. Solari A, Filippini G, Gasco P, Colla L, Salmaggi A, La Mantia L, et al. Physical rehabilitation has a positive effect on disability in multiple sclerosis patients. Neurol. 1999;52 (4):57-62. https:// dx.doi.org/10.1212/WNL.52.1.57

10. Wulf G, Weigelt C. Instructions about physical principles in learning a complex motor skill: to tell or not to tell. Res $Q$ Exerc Sport. 1997;68(4):362-367. https://dx.doi.org/10.1080 /02701367.1997.10608018

11. Schmidt RA, Lee TD. Motor control and learning: A behavioral emphasis. Human Kinetics Publishers; 2005:67-74.

12. Boyd LA, Winstein CJ. Impact of explicit information on implicit motor-sequence learning following middle cerebral artery stroke. Phys Ther. 2003;83(11):976-989. https://doi.org/10. 1093/ptj/83.11.976

13. Russeler J, Kuhlicke D, Munte TF. Human error monitoring during implicit and explicit learning of a sensorimotor sequence. Neurosci Research. 2003;47(2):233-240. https://dx.doi. org/10.1016/So168-0102(03)00212-8

14. Green REA, Shanks DR. On the existence of independent explicit and implicit learning systems: An examination of some evidence. Memory \& Cognition. 1993;21(3):304-317. https://dx.doi.org/10.3758/BFo3208263

15. Reber AS. Implicit learning and tacit knowledge. $J$ Exp Psychol Gen. 1989;118(3):219-224.

16. Cleeremans A. Principles for implicit learning. How implicit is implicit learning. Seminar Research in Sciences Cognitives. 1997:195-234.

17. Nissen MJ, Bullemer P. Attentional requirements of learning: Evidence from performance measures. Cognitive Psychol. 1987;19(1):1-32. https://dx.doi.org/10.1016/0010-0285(87) 90002-8
18. Pohl PS, McDowd JM, Filion DL, Richards LG, Stiers W. Implicit learning of a perceptualmotor skill after stroke. Phys Ther. 2001;81(11):1780-1789. https://dx.doi.org/10. 1191/0269215506cr916oa

19. Stefaniak N, Willems S, Adam S, Meulemans $\mathrm{T}$. What is the impact of the explicit knowledge of sequence regularities on both deterministic and probabilistic serial reaction time task performance? Memory \& Cognition. 2008;36(7):1283-1298. https://dx.doi.org/10. 3758/MC.36.7.1283

20. Song S, Howard Jr JH, Howard DV. Implicit probabilistic sequence learning is independent of explicit awareness. Learning \& Memory. 2007;14(3):167-176. https://dx.doi.org/10.1101/ $\operatorname{lm} .437407$

21. Robertson EM. The serial reaction time task: Implicit motor skill learning? J Neurosci. 2007;27(38):10073-10075. https://dx.doi.org/ 10.1523/JNEUROSCI.2747-07.2007

22. Green TD, Flowers JH. Implicit versus explicit learning processes in a probabilistic, continuous fine-motor catching task. $J$ Mot Behav. 1991;23(4):293-300. https://dx.doi.org/10.1080 /o0222895.1991.9942040

23. Green TD, Flowers JH. Comparison of implicit and explicit learning processes in a probabilistic task. Percept Mot Skills. 2003;97(3):299-314. https://dx.doi.org/10.2466/pms.2003.97.1.299

24. Curran T, Keele SW. Attentional and nonattentional forms of sequence learning. $J$ Exp Psychol Learn Mem Cogn. 1993;19(1):189-202. https://dx.doi.org/10.1037/0278-7393.19.1.189

25. Reber PJ, Squire LR. Encapsulation of implicit and explicit memory in sequence learning. $J$ Cogn Neurosci. 1998;10(2):248-63. https://dx.doi. org/10.1162/o89892998562681

26. Boyd LA, Winstein CJ. Implicit motor-sequence learning in humans following unilateral stroke: the impact of practice and explicit knowledge. Neurosci Lett. 2001;298(1):65-69. https:// dx.doi.org/ 10.1016/So304-3940(oo)01734-1

27. Boyd LA, Winstein CJ. Providing explicit information disrupts implicit motor learning after basal ganglia stroke. Learning \& Memory. 2004;11(4):388-396. https://dx.doi.org/10.1101/ $\operatorname{lm} .80104$ 
Original Article | Motor sequence learning and multiple sclerosis

28. Boyd LA, Winstein CJ. Explicit information interferes with implicit motor learning of both continuous and discrete movement tasks after stroke. J Neurol Phys Ther. 2006;30(2):46-57. https://dx.doi.org/10.1097/01.NPT.00002825 $66.48050 .9 \mathrm{~b}$

29. Howard DV, Howard JH. When it does hurt to try: Adult age differences in the effects of instructions on implicit pattern learning. Psychon Bull Rev. 2001;8(4):798-805. https://dx.doi. org/10.3758/BFo3196220

30. Bonzano L, Tacchino A, Roccatagliata L, Sormani M, Mancardi G, Bove M. Impairment in explicit visuomotor sequence learning is related to loss of microstructural integrity of the corpus callosum in Multiple Sclerosis patients with minimal disability. NeuroImage. 2011;57(5):495-501. https://dx.doi.org/10.1016/j.neuroimage.2011.04. 037

31. Tomassini V, Johansen-Berg H, Leonardi L, Paixao L, Jbabdi S, Palace J, et al. Preservation of motor skill learning in patients with multiple sclerosis. Mult Scler. 2011;17(1):103-115. https:// dx.doi.org/ 10.1177/1352458510381257

32. Kurtzke JF. Rating neurologic impairment in multiple sclerosis an expanded disability status scale (EDSS). Neurology. 1983;33(11):14441452. https://dx.doi.org/10.1212/WNL.33.11.1444

33. Fleiss JL. Statistical Methods for Rates and Proportions. New York, NY: John Wiley and Sons, Inc.; 1981.

34. Rao SM. Neuropsychology of multiple sclerosis. Curr Opin Neurol. 1995;8(3):216-222. https:// dx.doi.org/10.108o/01688638608405173

35. Stoquart-Elsankari S, Bottin C, Roussel-Pieronne $\mathrm{M}$, Godefroy O. Motor and cognitive slowing in multiple sclerosis: An attentional deficit? Clin Neurol Neurosurg. 2010;112(3):226-234. https://dx.doi.org/10.1016/j.clineuro.2009.11.017

36. Godefroy O, Lhullier-Lamy C, Rousseaux M. SRT lengthening: role of an alertness deficit in frontal damaged patients. Neuropsychologia. 2002;40(13):2234-2241. https://dx.doi.org/ 10.1016/Soo28-3932(02)00109-4
37. Honda M, Deiber M-P, Ibanez V, PascualLeone A, Zhuang P, Hallett M. Dynamic cortical involvement in implicit and explicit motor sequence learning. A PET study. Brain. 1998;121(11):2159-2173. https://doi. org/10.1093/brain/121.11.2159

38. Jenkins I, Brooks D, Nixon P, Frackowiak R, Passingham R. Motor sequence learning: a study with positron emission tomography. $J$ Neurosci. 1994;14(6):3775-3790.

39. Sakai K, Hikosaka O, Miyauchi S, Takino R, Sasaki Y, Pütz B. Transition of brain activation from frontal to parietal areas in visuomotor sequence learning. $J$ Neurosci. 1998;18(5):18271840. https://dx.doi.org/10.1.1.436.8328

40. Schlaug G, Knorr U, Seitz RJ. Intersubject variability of cerebral activations in acquiring a motor skill: a study with positron emission tomography. Exp brain research. 1994;98(3):523-534. https://dx.doi.org/10. 1007/BFoo233989

41. Beatty WW, Goodkin DE, Monson N, Beatty PA, Hertsgaard D. Anterograde and retrograde amnesia in patients with chronic progressive multiple sclerosis. Arch Neurol. 1988;45(6):611-619. https://dx.doi.org/10.1001/ archneur.1988.00520300029013

42. Litvan I, Grafman J, Vendrell P, Martinez JM, Junque C, Vendrell JM, et al. Multiple memory deficits in patients with multiple sclerosis: exploring the working memory system. Arch Neurol. 1988;45(6):607-610. https://dx.doi. org/10.1001/archneur.1988.00520300025012

43. Cader S, Cifelli A, Abu-Omar Y, Palace J, Matthews PM. Reduced brain functional reserve and altered functional connectivity in patients with multiple sclerosis. Brain. 2006;129(2):527537. https://dx.doi.org/10.1093/brain/awh670

44. Codeca C, Mori F, Kusayanagi H, Monteleone F, Boffa L, Paolillo A, et al. Differential patterns of interhemispheric functional disconnection in mild and advanced multiple sclerosis. Multiple Sclerosis. 2010;16(11):1308-1316. https://dx.doi. org/10.1177/1352458510376957 
45. Rocca M, Pagani E, Absinta M, Valsasina P, Falini A, Scotti G, et al. Altered functional and structural connectivities in patients with MS A 3 -T study. Neurology. 2007;69(23):2136-2145. https:// dx.doi.org/10.1212/o1.wnl.ooo0295504.92020.ca

46. Audoin B, Guye M, Reuter F, Au Duong M-V, Confort-Gouny S, Malikova I, et al. Structure of WM bundles constituting the working memory system in early multiple sclerosis: a quantitative DTI tractography study. NeuroImage. 2007;36(4):1324-1330. https://dx.doi.org/10. 1016/j.neuroimage.2007.04.038

47. Cercignani M, Bozzali M, Iannucci G, Comi G, Filippi M. Intra-voxel and inter-voxel coherence in patients with multiple sclerosis assessed using diffusion tensor MRI. $J$ Neurol. 2002;249(7):875-883. https://dx.doi.org/10. 1007/s00415-002-0752-y

48. Duong A, Boulanouar K, Audoin B, Treseras S, Ibarrola D, Malikova I, et al. Modulation of effective connectivity inside the working memory network in patients at the earliest stage of multiple sclerosis. NeuroImage. 2005;24(2):533-538. https://dx.doi.org/10. $1177 / 1352458509102907$
49. Bonzano L, Pardini M, Mancardi GL, Pizzorno M, Roccatagliata L. Structural connectivity influences brain activation during PVSAT in multiple sclerosis. NeuroImage. 2009;44(1):9-15. https:// dx.doi.org/10.1016/j.neuroimage.2008.08.015

50. D’Esposito M, Detre JA, Alsop DC, Shin RK, Atlas S, Grossman M. The neural basis of the central executive system of working memory. Nature. 1995;378(6554):279-281.

51. D’Esposito M, Onishi K, Thompson H, Robinson K, Armstrong C, Grossman M. Working memory impairments in multiple sclerosis: Evidence from a dual-task paradigm. Neuropsychol. 1996;10(1):51-56. https://dx.doi. org/10.1037/0894-4105.10.1.51

52. Rowland LA, Shanks DR. Sequence learning and selection difficulty. $J$ Exp Psychol Hum Percept Perform. 2006;32(2):287-299. https://dx.doi. org/10.1037/oog6-1523.32.2.287 